\title{
THE DISTINCTIVENESS OF DIGITAL CRITICISM
}

\author{
Sean Cubitt \\ Screen 41(1), Spring 2000
}

The core concern of media studies today is the material form of mediation. In whichever direction we take our analyses, the specificity of the discipline lies in its attention to the detailed functioning of textuality. The sociology of communication, the political economy of the media, the philosophy of media aesthetics are distinctive subdisciplines of other, older, fields of research. What distinguishes ours is the irreducible materiality of mediation. We can perhaps feel that we are less prone to overgeneralisation, mythmaking and simple errors of fact because of that attention; and that we are in a better position to make statements about audiences, institutions, economies, societies, cultures and aesthetics because we have spent long years, both individually and as a research community, looking at the minutiae of historical and contemporary media. And yet we seem to have betrayed the digital media not only in the failure to archive electronic media but intellectually too: in the half-acceptance of a view that the digital media in some way effective dematerialisethe older media. Once dematerialised, media can no longer fall into our field or, alternatively, we are confronted with the proposal that we abandon the central object of our studies, the materiality of the text, and remake ourselves in the theoreticis mould with which the US academy in particular greeted the embarrassingly political discourses of 1970s 'Screen Theory'. As literary theory has pursued the dematerialisation of the book, print, paper and inks in the abstraction of the text, so media studies faces a choice between dematerialising and rematerialising its object.

The challenge posed by 'new' media criticism is then not simply one of extending and evolving critical principles in an established paradigm. It is a challenge to the fundamentals of the discourse which potentially alters the terms under which it is possible to study and analyse the media, their functioning and their origination. The influential attempts to account for the supposed impact of digital media on postmodern societies among such commentators as Lyotard, Virilio and Baudrillard [FN1] derive from the early cybernetic paradigms of information science, and in particular the abstract concept of information promulgated by Shannon, Weaver, Wiener and von Neuman [FN2]. But as N Katherine Hayles points out, that conception of information as pattern, order and system was already in crisis during the Macy conferences which translated it from engineering solution to scientific paradigm [FN3]. In the media studies context, it is important to understand the developments in information science since the 1940s, not least as its most recent and most compelling variant, the concept of complexity or emergence, not only occupies a central role in digital cinema and computer graphics generally, but has provided, in the form of artificial life, the latest in apologies for self-regulating capitalism [FN4].

Familiarly known as 'chaos theory', the concept of emergence theorises that in certain complex systems, including planetary weather systems and some chemical reactions, chaotic states can give rise to new, spontaneously generated states of order and stability. Extended by analogy to social and cultural systems, the paradigm of emergence rasies specific problems for the problematic of representation. On the one hand, it is clear that digitally-generated images and sounds have as only one of their possible functions the representation of previously existing objects: the 'virtual' image, in Margaret Morse's definition, is 'meant to shape or invent a world, not to represent it' [FN5]. But on the other, as Hayles has it, 'Virtuality is the cultural perception that material objects are 
interpenetrated by information patterns' [FN6]. Hayles' definition relies upon information science's conceptualisation of the reflexive relations between systems (such as animals or machines), their environments and their observers. The imaging of a fantasy world is not without relation to the unimaged world into which it is born, from which it derives its fantasia, in which it exists both as information and as representation of information, and in which it functions. But in a host of ways, computer technologies throw themselves open to the chaotic emergence of unforeseen order, to accident, chance and the recursive workings of software algorithms over which the designer has only the limited creative power to choose between possible outcomes. It is in this sense that digital devices have acquired the aura of co-creator: authors as well as stars of films like Toy Story (1997) become therefore cyborgs in the limited sense of hybrid human/machine entities.

The question for digital media critics then no longer concerns the figuration of a previously existing world but rather of the nature of the communication between human and mechanical authors, and between those cyborg authors and their co-communicators in the audience. In the case of interactive media like games and some digital artworks, one line of thought sees the extension of users' control over the text. But a now common counterargument reads the 'audience' from the point of view of the machine, from whence they appear as effectively random number generators, as the host environment to which the authored work responds, and in which it is increasingly empowered to evolve out of the control of both originators and audience. This offers the grounds for discussion of the relations between media and non-media far more complex than that allowed by the relatively simple problematic of representation.

The necessity to construct a field of argumentation concerning the changing terms of the relation between mediation and 'reality' has led a number of research pioneers to attempt to define the digital in terms of its difference from the photomechanical media, especially in the area of photography [FN7]. The distinction often operates on the intuited gap between the physical and digital manipulation of images, and has proved a valuable tool in understanding the nature of the transition from photomechanical to digital photography. But as a paradigm for future research, it leaves much to be desired, since it rests implicitly -- and sometimes explicitly -- on a conceptualisation of the mechanical photograph as normative, and the digital as a deviation from that norm. Rather as the classical narrative film threatens to become the universal norm from which all other forms of cinema derive, the notion of mechanical media as normative must be challenged if digital criticism is to come of age.

This norm-deviation structure of argument extends to studies in hypertextual narration [FN8]. Since media studies has until now quite properly associated itself with entertainment media, it has largely divorced itself from studying the instrumental use of images in the workplace. But the digital media derive only some of their techniques from entertainment media and the associated structures of representation and narration. At least equal weight needs to be given to non-narrative conventiuons for organising and transmitting information: cataloguing and accountancy, and such modes of visualisation as cartography and graphic display, for example. Each of these modes of structuration, assembly and retrieval is in certain senses realist, more so in many ways than the conventions of novelistic narrative and perspectival drawing. Such structures are certainly non-linear, but their origins in book-keeping, bureaucracy and imperialism suggest that they should not be naïvely construed as simply anti-narrative. Since many digital technologies rely neither on narration nor illusion, the digital critic can no longer depend on the presumed dominance of narrative and picturing to orient their evaluations of specific digital works. 
Nonetheless, the question of evaluation is a pressing one for digital critics, not least because of the monopoly structure of the underlying industry and the inequalities exacerbated by global networks [FN9]. Some earlier positions persist. There are still liberal, 'luddite' critics for whom digital culture heralds the death of literate and humane society. Equally, there are still libertarian 'cybertopians' for whom each new device is evidence of ineluctible, technological progress [FN10]. But the more convincing social critics of digital culture develop more subtle arguments concerning the cultures of work, politics and community, drawing on existing media sociological paradigms such as the panopticon without constructing simple oppositions between, for example, private good versus 'surveillant' bad [FN11]. In my own work, I have argued that the death of privacy should be embraced in order to hasten the corollary death of private property, already deeply threatened by the insecurity of internet commerce and the incapacity of copyright laws to regulate, practically or morally, the claims of intellectual property rights. On this basis I propose an aesthetic evaluation based on the opportunity afforded by network anonymity to espouse a dialectic of the public and the intimate [FN12]. Other critics have argued for more explicitly political criteria, inspired by the 'tactical' use of network communications to futher the politial goals of such groups as peasant insurgents, ecological campaigners and neo-situationists [FN13]. In both cases, evaluation is grounded in novel modes of socialisation enabled by computer-mediated communications

Critical to the development of any genuinely new media practices and evaluative criteria are the understandings gleaned from debates in numerous online forums concerning the nature of the emergent mediascape. For many years, digital critics have dependended on corporate histories and exposés and hagiographic journalism for the bones of a history of the digital media. As new scholarship provides a more thorough historical grounding in the history [FN14], we can assess repeated claims of innovation, convergence, spiritualism, conspiracy theory, defeatism and utopianism. Just as cinema analysts are no longer satisfied with simply spotting ideologies in films, so digital critics are beginning to analyse more complex interactions involving the defense industries, universities and the US military in the development of network technologies, and the influence of quite different research scenarios feeding into early networking techniques from Europe and Asia. These histories are to date overwhelmingly US-oriented: an urgent task for digital media studies is the creation of a body of scholarship on the development of hardware, software and webware globally. Once such work is in place, including critical and analytical interpretations of the value structures of specific technologies [FN1], it will be far more possible to understand the specific qualities of audiovisual experience that shape our interactions withthe computer and the semantic worlds in which producers operate in the production of digital texts.

To some extent this is simply a call to extend existing paradigms in film and television studies. But with digital media, the qualities of interaction are not solely psychological. Digital media involve us in distinctive text-user relations, involving for example physical interactions with software. Games, word-processing, image generation and manipulation, sound editing, 3D modelling and network packages all demand bodily engagement on the part of the end-user. In this sense the 'text' of digital media is not a fixed entity but the ephemeral production of users' interactions with the medium. From one point of view this represents the diminution and dematerialisation of textuality: without the permanence of the model text, there is no object for textual analysis. Since the digital interface is by nature fleeting and changeable, textuality resides primarily in the flow of interactions, and only marginally in end-products like digital animations and 3D models. Digital cinema also demands an understanding of the levels and orders of interactions into which it enters with 
its audiences. For example, what was once the peripheral marketing of associated toys, games and consumer goods associated with the first Star Wars film (1977) is now integral to the production of Star Wars Episode One: The Phantom Menace (1999). Not only does the film contain clear indications of the computer games and theme park rides that will be developed from it; such spin-offs are designed at the same time as the film, sharing code with the digital special effects which are designed in order to provide for swift re-use of animations and models in new products. Even the computer-aided manufacture of Star wars toys now employs the very same $3 d$ models as the film itself.Effectively, the film and its associated entertainments comprise a single, extended and highly interactive text.

Extended textuality and ephemerality also raisequestions about temporality. The first generation of cybercritics has been largely concerned with the production of (cyber)space: its successors will address the manipulation of cybertime. To a degree, film and television have already pre-empted that revolution in spatial perception commonly attributed to digital media. The specificity of digital media however lies in their complex layering of temporalities. Extreme temporal states, for example freezes and crashes, are woven into realtime interactions with the machine, delayed time interactions with 'live' interlocutors, download times, boot-up times, downtime and lagtime, refresh rates and the constant balancing of quality against processing time performed by every user of modelling, imaging and sound-editing software. These temporalities are integral to the experience of computing, and increasingly enter the myths of our era (notably the myth of instantaneity) become part of the increasingly sophisticated manipulations of time in other media, especially cinema. Time itself is becoming a raw material for creative production. Simultaneously, the time and quality of users' attention is the commodity most highlyvalued by internet advertisers and traders. The time of the click, the nomadic time of the browser, extends the extraneous channel-zapping of the television remote control into an active principle of the medium itself. These new forms of temporality will form an important aspect of new digital criticism.

While there is now a substantial literature on film music, sound continues to receive less attention [FN16]. Digital sound, however, has attracted some substantial attention, notably from Douglas Kahn and the group around Essays in Sound [FN17]. Typography and graphic design, rarely addressed in film and television criticism, or even in contemporary literary studies, also require attention because of their major role in digital media. The ephemeral materiality of fonts, sound cues, hyperlinks and the detailed peculiarities of games, software and network product need to be recognised both theoretically and practically. If media studies cannot demonstrate familiarity with at least the basic terminology of software culture, how are we to persuade an increasingly computer-literate public that we have anything valuable to say?

A central claim of cybercultural discourse is that computer-mediated communication promotes democratisation. One of the things media studies should offer to this democratisation of the media is the publicising of alternative cultural practices. Rather than decry the limited aesthetic ambition of amateur culture, might we not be better employed liaising between amateur and artistic zones? Over the last ten years, the digital media arts have become especially fruitful areas for the development of political aesthetics [FN18]. For example, numbers of media artists have developed online and gallery installations whose social and sociable interfaces provide alternatives to the competitive individualism of the standard desktop workstation. The width and variety of digital art practice is immense, and the networks for professional communication highly developed. What is lacking is a critical discourse open to the general public, especially to those who build their 
own websites or synthetic landscapes as hobbyists, but who crave broader vistas and more challenging ideas.

In the meticulous reading of digital media, especially of amateur, tactical and art media, media studies stands to gain not only an understanding of the 'new' media, not only a redefinition of older disciplinary precepts, and not only a serious rethinking of some major principles of media studies, but new avenues of analysis that are rendered thinkable by media innovation. The immediate challenge is to develop an appropriate, specific and material vocabulary for digital criticism.

\section{FOOTNOTES}

1. Notably Jean-François Lyotard, The Postmodern Condition: A Report on Knowledge, trans Geoff Bennington and Brian Massumi, (Manchester: Manchester University Press, 1984); Paul Virilio, The Vision Machine, trans Julie Rose (London: BFI, 1994); and Jean Baudrillard, Symbolic Exchange and Death, trans lan Hamilton Grant, (London: Sage, 1993).

2. Claude E. Shannon and Warren Weaver, The Mathematical Theory of Communication, (Urbana: University of Indiana Press, 1949); Norbert Wiener, Cybernetics or, Control and Communication in the Animal amd the Machine (Cambridge MA: MIT Press, 1948) ; Norbert Wiener, The Human Use of Human Beings: Cybernetics and Society, (London: Free Association Books, 1950); Steve Heims, John von Neumann and Norbert Wiener, (Cambridge MA.: MIT Press, 1980).

3. N. Katherine Hayles, How We Became Posthuman: Virtual Bodies in Cybernetics, Literature and Informatics, (Chicago: University of Chicago Press,1999),

4. The argument that information theory's paradigm of the emergence of order from chaotic interactions can provide a rationale for the functioning of unregulated capitalism and 'free markets' is most closely associated with the digital lifestyle journal Wired. See for example Wired staff writer Kevin Kelly's, Out of Control: The New Biology of Machines, (London: 4th Estate,1994); on the paradigm of emergence in general see Claus Emmeche, The Garden in the Machine: The Emerging Science of Artificial Life, (Princeton: Princeton University Press,1994); Steven Levy, Artificial Life: The Quest for a New Creation, (Harmondsworth: Penguin,1992); llya Prigogine and Isabelle Stenghers, Order Out of Chaos: Man's New Dialogue with Nature, (London: Flamingo,1988); M Mitchell Waldrop, Complexity: The Emerging Science at the Edge of Order and Chaos, (Harmondsworth: Penguin,1992).

5. Margaret Morse, Virtualities: Television, Media Art, And Cyberculture, (Bloomington: Indiana University Press, 1998), p. 21

6. N Katherine Hayles, How We Became Posthuman: Virtual Bodies in Cybernetics, Literature and Informatics, (Chicago: University of Chicago Press, Chicago, 1999), p.13 7. Among them are the authors collected in Derek Bishton, Andy Cameron and Tim Druckery (eds), Digital Dialogues: Photography in the Age of Cyberspace, Ten:8 Photo Paperback vol 2 n.2, Autumn (1991); also Sarah Kember, Virtual Anxiety: Photography, New Technologies and Subjectivity, (Manchester: Manchester University Press, 1998); William J. Mitchell, The Reconfigured Eye: Visual Truth in the Post-Photographic Era, (Cambridge, MA: MIT Press, 1992); Kevin Robins, Into the Image: Culture and Politics in the Field of Vision, (London: Routledge, 1996); Fred Ritchin, In Our Own Image: The Coming Revolution in Photography, (New York: Aperture Foundation,1990).

8. Among the major texts and collections are Jay David Bolter, Writing Space: The Computer, Hypertext and the History of Writing, (Hillsdale NJ: Lawrence Erlbaum Associates, 1991); Michael Joyce, Of Two Minds: Hypertext, Pedagogy and Poetics, (Ann Arbor: University of Michigan Press, 1995); Michael Heim, Electric Language: A Philosophical Study of Word Processing, (New Haven: Yale University Press, 1987); 
George P. Landow, Hypertext: The Convergence of Contemporary Critical Theory and Technology, (Baltimore MD: Johns Hopkins University Press, 1992); George P. Landow (ed), Hyper/Text/Theory, (Baltimore MD: Johns Hopkins University Press, 1994).; Janet H. Murray, Hamlet on the Holodeck: The Future of Narrative in Cyberspace, (Cambridge MA: MIT Press, 1997).

9. The already classic study of the global impact of information technologies is Manuel Castells', The Information Age: Economy, Society and Culture volume One, The Rise of the Network Society, (Oxford: Blackwell, 1996); volume Two, The Power of Identity, (Oxford: Blackwell, 1997); volume Three, End of Millenium , (Oxford: Blackwell, 1998); see also Dan Schiller, Digital Capitalism: Networking the Global Marketing System, (Cambridge MA : MIT Press, 1999).

10. Among the more influential 'luddite' arguments are those of Sven Birkerts, The Gutenberg Elegies: The Fate of Reading in an Electronic Age, (London: Faber, 1994) and Neil Postman, Technopoly: The Surrender of Culture to Technology, (New York: Vintage, 1992). For examples of 'cybertopian' arguments, see Nicholas Negroponte, Being Digital, (London: Coronet, 1995) and Howard Rheingold, The Virtual Community: Homesteading on the Electronic Frontier, (New York: HarperCollins, 1993). It is sobering to note that the lyrical utopianism of computer scientist David Gelernter earnt him the murderous attentions of the Una bomber: see his Mirror Worlds, or, The Day Software Puts the Universe in a Shoebox ... How It Will Happen and What It Will Mean, (Oxford: Oxford University Press, 1991); The Muse in the Machine: Computers and Creative Thought, (London: 4th Estate, 1994) and The Aesthetics of Computing, (London: Phoenix, 1998). 11. See for example Stanley Aronowitz, Barbara Martinsons and Michael Menser (eds), Technoscience and Cyberculture, (London: Routledge, 1996); Stanley Aronowitz, and Jonathan Cutler (eds) , Post-Work: The Wages of Cybernation, (London: Routledge, 1998); Brian D. Loader (ed), The Governance of Cyberspace: Politics, Technology and Global Restructuring, (London: Routledge, 1997); John Downey and Jim McGuigan (eds), Technocities, (London: Sage, 1999).

12. Sean Cubitt, Digital Aesthetics, (London: Sage, 1998).

13. For example Geert Lovink, publishing as ADILKNO (Foundation for the Advancement of Illegal Knowledge), Media Archive, (New York: Autonomedia, 1998).

14. See for example Janet Abbate, Inventing the Internet, (Cambridge MA: MIT Press, 1999); Paul E. Ceruzzi, , A History of Modern Computing, (Cambridge MA: MIT Press, 1999); Paul N. Edwards, , The Closed World: Computers and the Politics of Discourse in Cold War America, (Cambridge MA: MIT Press, 1996).

15. See for example the work of Friedrich A. Kittler on computing and some of the technologies that have contributed to its development in the books Discourse Networks 1800/1900, trans Michael Metteer with Chris Cullens, (Stanford: Stanford University Press, 1990); , Literature, Media, Information Systems: Essays ed and intro John Johnston, (Amsterdam: G+B Arts International, 1997); Kittler, Friedrich A, Gramophone, Film, Typewriter, trans and intro Geoffrey Winthrop-Young and Michael Wutz, (Stanford: Stanford University Press, 1999).

16. The major exceptions are in the work of Michel Chion and of Rick Altman and his associates. See notably Michel Chion, Le Son au cinéma, (nouvelle edition), (Paris: Cahiers du Cinéma, Collection Essais, 1992); and Rick Altman (ed) , Sound Theory/Sound Practice, (London: Routledge, 1992).

17. See for example Douglas Kahn and Gregory Whitehead (eds), Wireless Imagination: Sound, Radio and the Avant-Garde, (Cambridge, MA: MIT Press, 1992) and John Potts, , 'Schizochronia: Time in Digital Sound' in Essays in Sound 2, (Sydney: Contemporary Sound Arts, 1995) np.

18. Among the best introductions to the digital media arts are Timothy Druckrey(ed), Electronic Culture: Technology and Visual Representation, (New York: Aperture, 1996); 
Timothy Druckrey with Ars Electronica (eds), Ars Electronica: Facing the Future, (Cambridge MA: MIT Press, 1999); Peter Lunenfeld (ed), The Digital Dialectic: New Essays on New Media, (Cambridge MA: MIT Press, 1999); Mary Ann Moser with Douglas MacLeod (eds), Immersed in Technology: Art and Virtual Environments, (Cambridge MA: MIT Press, 1996); Simon Penny (ed), Critical Issues in Electronic Media, (Albany NY: State University of New York Press, 1995). 


\section{University Library}

\section{- M M N E R VA A gateway to Melbourne's research publications}

Minerva Access is the Institutional Repository of The University of Melbourne

Author/s:

CUBITT, SEAN

Title:

The distinctiveness of digital criticism

Date:

2000

Citation:

Cubitt, S. (2000). The distinctiveness of digital criticism. Screen, 41(1), 86-92.

Publication Status:

Published

Persistent Link:

http://hdl.handle.net/11343/34896 